
\title{
Communication, symbolic play, and play-extension in pre-school,
hearing-impaired children
}

\author{
Denise E Segal, MA (Speech Pathology) (Witwatersrand) \\ Speech Therapy Department \\ Hillbrow Hospital, Johannesburg
}

\begin{abstract}
The relation between play and communication was investigated in a sample of congenitally hearing-impaired, pre-school
children. A sample of hearing children served as a guide for the 'normal' course of children. A sample of hearing children served as a guide for the 'normal' course of development. The children's use of their com-
munication modalities during play and particularly play-extension, or the ability to extend beyond materials, was assessed. The same children had been assessed previously in terms of extend beyond the immediacy of the play independent of communication. These findings served as a baseline for in terms of symbolic and non-symbolic play activities based approach was adopted, with performance emphasized. Results the present study. An observational and ethologically'move away from' the immediate play context although they used communication the hearing-impaired children attained no tion is important during play, subsequent to the onset of symbolism in plation during play. It was suggested that communicaissues pertaining to the relationship between language and cognition play. Findings are discussed in the light of theoretical sign language. Clinical suggestions and implications for future research are offered
\end{abstract}

\section{OPSOMMING}

Die verwantskap tussen spel en kommunikasie is in 'n groep kongenitaal-gehoorgestremde voorskoolse kinders ondersoek. 'n munikasie modaliteite tydens spel en veral spel-ekstensie normale ontwikkeling geneem. Die kinders se gebruik van hulle komis beoordeel. Dieselfde kinders is voorheen ten opsigte van vermoë om spel verder as die onmiddellike spelmateriaal te voer. munikasie) beoordeel. Hierdie bevindinge het as grondslag vir dieliese en nie-simboliese spelaktiwiteite (onafhanklik van koming is gehandhaaf waar gedrag beklemtoon is. Daar is gevind dat die gehoorgestrem. ' $n$ Warnemings en etologiese benaderspelkonteks kan wegbeweeg nie alhoewel hulle tydens spel gekommunikeer het Dit word spelsituasie belangrik is, maar slegs na die aanvang van simboliese spel. soos die verhouding tussen taal en kognisie, die rol van gebare en die spel. Die bevinding word in die lig van teoretiese aspekte wenke en implikasies vir verdere navorsing geniet aandag.

The universal nature of play both across species and across cultures has long been recognised. Play has been viewed as a vital and predominant activity of childhood. ${ }^{6}$ However, only recently has it been regarded as a possible clue to understanding children and to gaining insight into the motives underlying human behaviour. ${ }^{9}$

The congenitally hearing-impaired child has continually been the victim of academic conjecture. Recently, hearing-impaired their hearing been regarded as behaviourally equivalent to these ching peers, a move away from the earlier view that education were retarded or concrete-bound.' However, impairment acknowledge the profound effect that hearing consequently, on the development of verbal language and majority of studies development of communication." The have indicated a (such as that by Power and Quigley) ${ }^{14}$ gression. Neverthelayed rather than different linguistic proimportant in Die Suid-1frikanse development remains contentious, and

(c) SASHA 1983 there have been comparatively few studies of cognition and its relation to language and play in this population group.

Symbolic play and gesture are believed to be derived from the same developmental roots, 8,23 with symbolic play a progression from early gestures and an integral part of communication development. The close association between play, verbal language and gesture during the course of development, highlights the importance of assessing symbolic play in hearing-impaired children. Researchers, for example, GoldinMeadow and Feldman, have concluded that the visual modality equals the auditory modality as a medium for language learning and that the hearing-impaired child favours the visual modality.

Recent investigations have tended to support Piaget's hypothesis $^{12}$ which emphasizes that cognition forms the basis for all intelligent behaviour including language. Piaget argues that language is not an essential prerequisite for symbolic play 
development. ${ }^{12}$ However, Vygotsky's position ${ }^{21}$ in relation to that of Piaget has not been clarified and it suggests that language may assume an important role subsequent to the onset of symbolic play. Studies with older hearing-impaired children (for example that by Prutting and Skarakis) ${ }^{16}$ have generally indicated a parallel performance on cognitive tasks in which verbal language is not an inherent part of the task itself. Relatively few studies of this nature have investigated the pre-operational period even though symbolic play, being observable, lends itself to investigation. The hearing-impaired child is particularly difficult to assess because the majority of play scales include language, whether directly or indirectly. ${ }^{19}$ The hearing-impaired child may use gesture or sign language during play, similar to the hearing child's use of language (except that the play sequence would be temporarily interrupted by a gestural movement). For this reason, a play analysis has either to exclude language altogether, or, to include all communication modalities and not verbal language alone. The hearing-impaired child's use of any compensatory modality other than that of verbal language would suggest that verbal language is important at this early stage of cognitive
development.

The term 'Symbolic Play' was applied in accordance with Piaget to refer to a behaviour in which assimilation predominates over accommodation allowing for "the deformation and subordination of reality to the desires of the self"'. ${ }^{13}$ It is implicit that the behaviour occurs out of context and that the child is aware of the distortion of reality. The present researcher applied the term only to that which was observable from the child's performance, drawing no inferences
about his competence.

The term 'Play-Extension' was coined by the present researcher ${ }^{18}$ to refer to the process of "going beyond the information given" 2 within the narrow context of play. This refers to the process of 'moving away from' the play materials within the play situation, rather than moving away from the play situation itself. Play-extension is viewed along a continuum with 'immediacy' providing the earliest stage and 'nonimmediacy' the most advanced stage. ${ }^{8}$ It is argued that verbal language may play an important role during the preoperational stage of development, subsequent to the onset of symbolic play, rather than as a prerequisite for the emergence of symbolic play. If symbolic play is assessed independently of communication in hearing-impaired children, a finding of delayed or different play performance would suggest either that verbal naming, specifically, is required for the onset of symbolic play, or that a gestural or signing method is not as efficient as verbal naming in this process.

The present researcher was concerned with the qualitative changes that occur in play and communication and with their continual interaction during the course of development. A quantitative measure was considered to be too broad to reflect the subtle changes which are important for clinical practice. ${ }^{17}$ In addition, it was aimed to use passive observation and description as an aid to diagnosis and therapy for the hearingimpaired child in conjunction with findings from the study of normal children, rather than relying upon the latter alone. It must be emphasised that the early effects of congenital hearing impairment on verbal language complicate the separation of general experiential differences from the effect of communication differences, on subsequent development. ${ }^{22}$ For this reason, in the theoretical questions posed, the role of verbal language necessarily implies the factor of general experience
as well.

On the basis of the above, the present study investigated playextension, that is, the child's use of communication modalities during play. Prior to this, symbolic play was assessed in terms of play type and play complexity along a scale derived from Piaget's ${ }^{12}$ categories and along the Lunzer ${ }^{6}$ scale, respectively, This preliminary study is not included in the present paper. However, in summary, it was found that, at a non-verbal level, where any form of communication was excluded from the analysis of play, the hearing-impaired children demonstrated equivalent play complexity to their hearing peers with a delay in symbolic play activities. ${ }^{18}$ This then served as the basis for
analysis of play-extension.

The purpose of the present study was to determine whether the hearing-impaired child uses his communication modalities during play and, if so, whether he uses communication to extend play beyond the immediacy of the play materials. Clinically, this study aimed to assist speech and hearing therapists by providing therapeutic insights into the general play behaviour, aspects of communication and abstracting abilities (that is, ability to 'move away from' the immediate context) of the small sample of hearing-impaired children. Furthermore, it aimed to clarify some of the vagueness surrounding the field of play as well as attempting some elucidation of the ill-understood relation between verbal language and
cognition.

\section{METHODOLOGY}

\section{SUBJECTS}

A total of ten white children of middle class South African families, aged between 15 and 41 months, served as subjects. The experimental group comprised 5 hearing-impaired children who presented with severe congenital hearing losses and who had been fitted with hearing aids between 8 and 12 months of age. Five hearing children were matched with the experimental subjects for chronological age and sex (see Table I). It must be emphasised that this sample of hearing children did not comprise a control group. Rather, it constituted a sample from which to ascertain guidelines for a developmental sequence for play-extension. No attempt wasimade in analysis to compare individual hearing-impaired subjects with the associated hearing peer.

From Table I below it can be seen that an age bias always favoured the hearing-impaired children. The age range included the 18-month level for the onset of symbolic play as well as the 3-4 year peak of development. ${ }^{12}$

All children were of average intelligence and presented with no primary emotional problem or concomitant neurological or physical handicap. Impairment of language or hearing was ruled out with regard to the 'normal' subjects. All hearingimpaired subjects were attending the Unit for HearingImpaired Children, University of the Witwatersrand, which afforded daily speech and language therapy, auditory training and parent counselling. Children taught sign language would 
Table 1 Age and Sex Characteristics of the Subjects

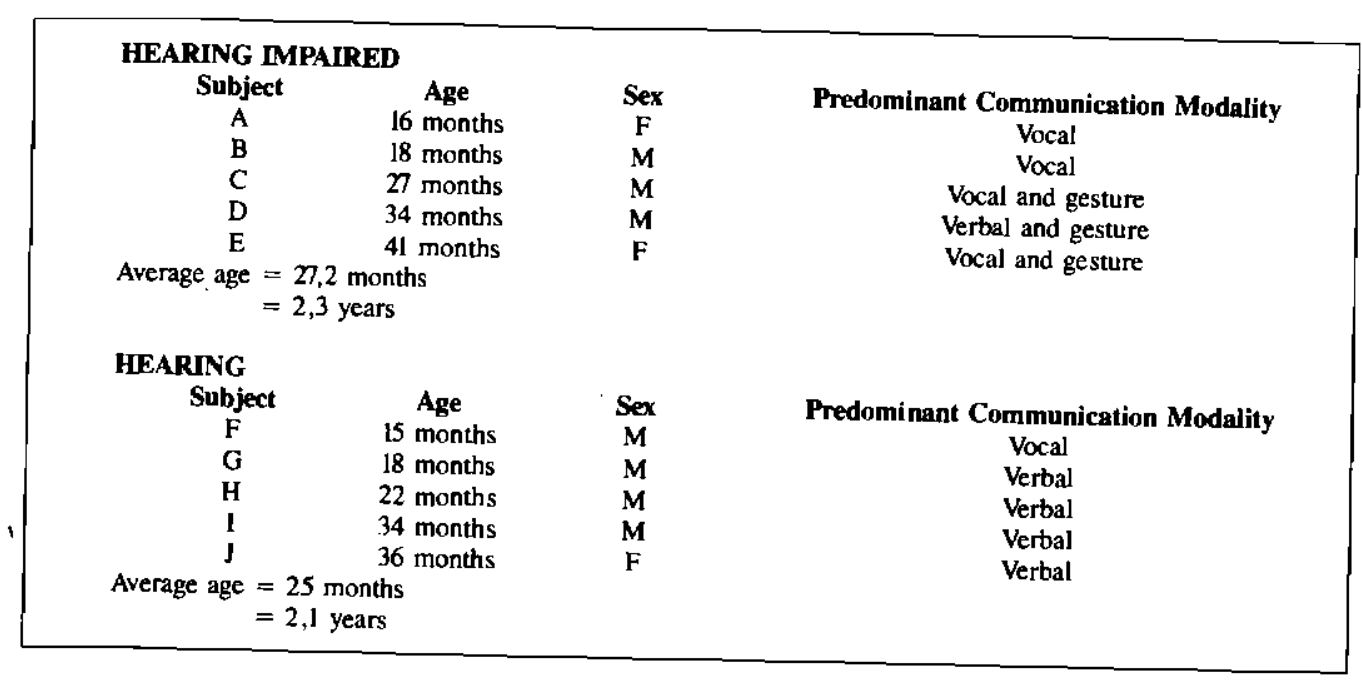

have been communicating at a level equivalent to that of normal children using verbal language ${ }^{5}$ For this reason, it was necessary to investigate children taught by oral-aural means in order to be able to answer the question concerning the role of verbal language in symbolic play

\section{RATING SCALES}

A rating scale for play-extension was compiled on the basis of observation of the sample of hearing and hearing-impaired children. An ethologically-oriented approach ${ }^{3}$ was adopted in that categories were formulated to describe the observed behaviours rather than 'squeezing' the behaviours into previously devised categories. The subjectivity of the behaviours themselves, and of the rating by a single judge, are recognised as limitations. All behaviours involving language only, play only, or extension beyond the situation itself (versus play-extension) were assigned a score of 0 since only the simultaneous occurrence of play and communication was of interest. A score of 0 therefore implies a lower level only with regard to the interest of the present investigator and to the nature of the behaviours being investigated. Levels 1-5 accord with the broad category of 'immediacy' indicating that the child is bound to the immediate context. Levels $6-8$, the broad category of 'non-immediacy', indicates that there is a 'move away from' that which is immediately present. From level 5 , Mehrabian's framework ${ }^{8}$ was found to be no longer applicable since it describes development of communication per se, thereby deviating from the emphasis in the present study. Vocal, verbal and gestural means of communication are included in the scale. ${ }^{18}$

\section{PROCEDURE}

Each child, alone with his/her mother was videotaped from behind a one-way mirror in an unstructured nursery school setting at the University of the Witwatersrand Unit for Hearing-Impaired Children. A Sony Betamax video cassette recorder (model SL8000) was used. The environment comprised a full selection of play materials which was designed to materile self-initiated, spontaneous child activity. The play 'junk' comprised commercially available objects as well as erial.

\footnotetext{
Three sessions per child were recorded at two-month intervals

Die Suid-Afrikaanse Tydskrif vir Kommunikasieafwykings, Vol. 30, 1983
}

so as to tap peak periods in development as well as the progression over time. The experimenter then described the ongoing play behaviours from the videotape onto a tape recorder while two raters simultaneously rated these behaviours.

An index of inter-rater consistency was established by summing those categories that were rated the same by both judges and by computing the ratio of these judgements to the total number of judgements made. Values above 0,8 were considered to reflect high consistency. Measures obtained were 0,$86 ; 0,92 ; 0,81 ; 0,83 ; 0,93$; and 0,81 .

The verbal description was transcribed in written form and checked for objectivity and accuracy by another independent observer. This served as the data for derivation of the playextension scale. Separate scales were drawn up for verbal, vocal and gestural modalities, which were subsequently coordinated. A time-sampling procedure was favoured despite its 'unnatural' quality, since event-sampling is problematic when rating vocal behaviour ${ }^{18}$. Every ten-second period constituted a unit of analysis, and each behaviour within a ten-second period was analysed into type and extension categories.

Communication is frequently of brief duration, however duration bears no relation to play-extension. As an example, a brief utterance such as, "they're home", may alter an entire sequence of behaviours and imply a complex extension. Timesampling was a suitable compromise to overcome some of these difficulties. Since many levels may occur within any one play event, only the focal behaviour for any ten-second period was scored. ${ }^{10}$ At the higher levels of play-extension in which events are difficult to separate into isolated units, cohesion was afforded by means of this procedure. Lower levels, if not focal, were excluded in rating.

Whether or not one is able to accurately interpret what a child is attempting to express in his play, is questionable. It is evident that the researcher is limited to that which the child chooses to display overtly or to communicate. For this reason, the present study was concerned exclusively with performance. An example which will serve to highlight these difficulties is evident when one is presented with two children, one of whom has adequate verbal facility and the other, a nonverbal child. When both children draw circles, the verbal child 
Denise S. Segal
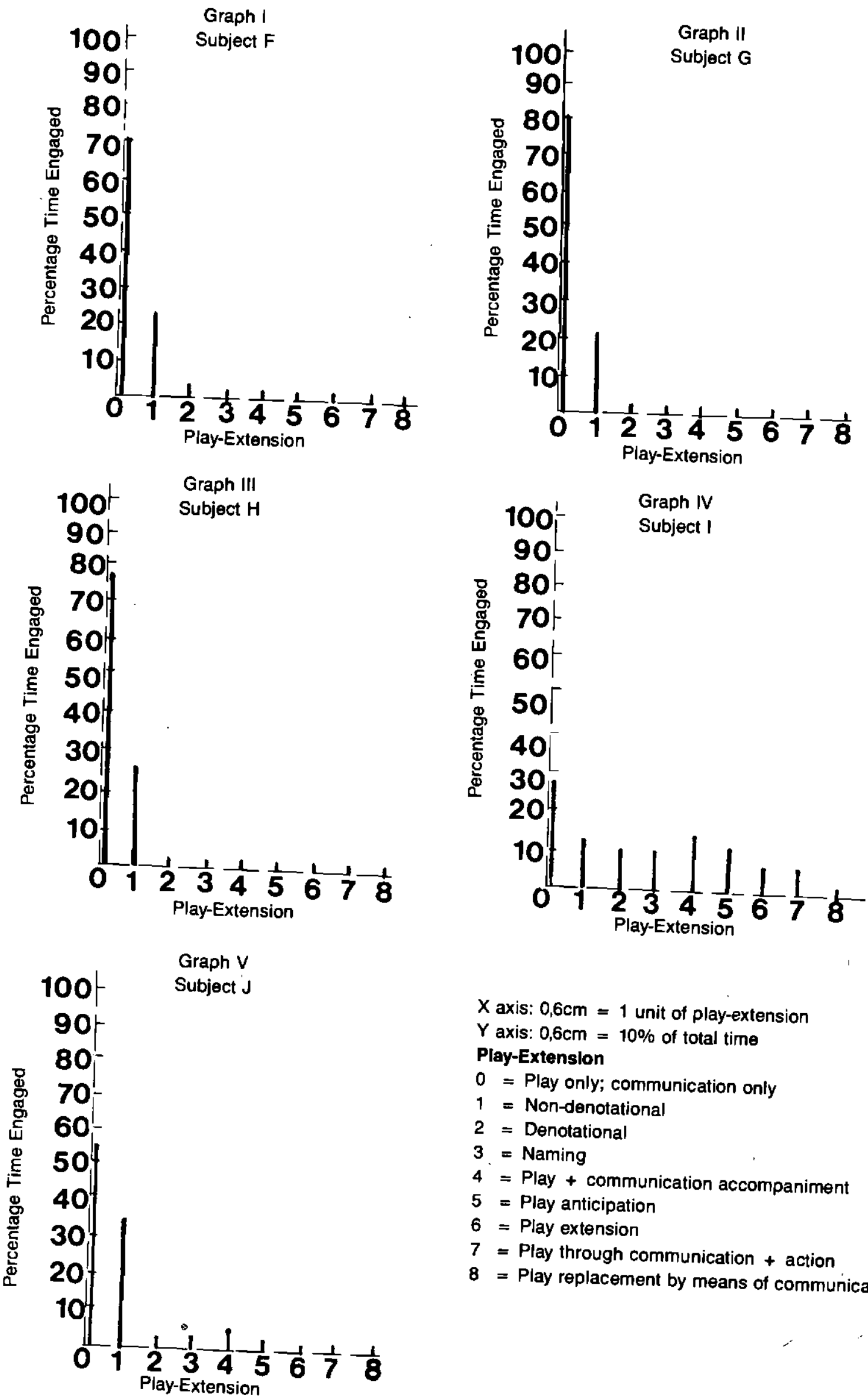

$X$ axis: $0,6 \mathrm{~cm}=1$ unit of play-extension

$Y$ axis: $0,6 \mathrm{~cm}=10 \%$ of total time

Play-Extension

0 = Play only; communication only

1 = Non-denotational

2 = Denotational

$3=$ Naming

4 = Play + communication accompaniment

5 = Play anticipation

6 = Play extension

7 = Play through communication + action

8 = Play replacement by means of communication

Figure 1 Percentage of total time engaged in play-extension with the three sessions combined for the hearing-impaired
subjects. 
Graph I

Subject A
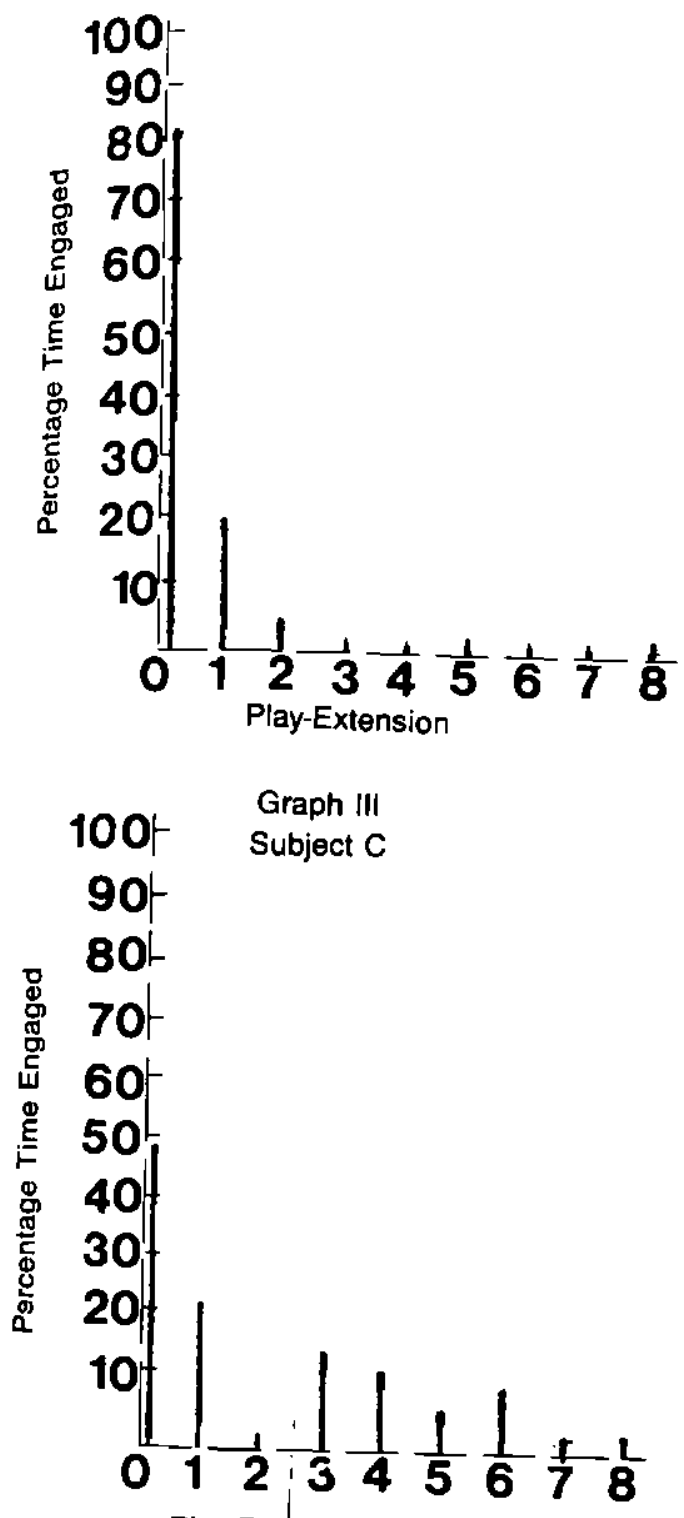

Play-Extension

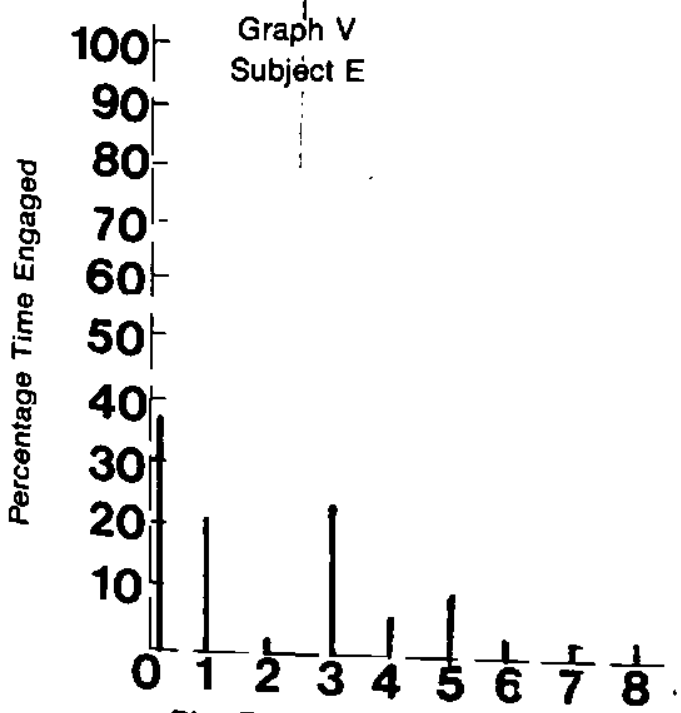

Play-Extension
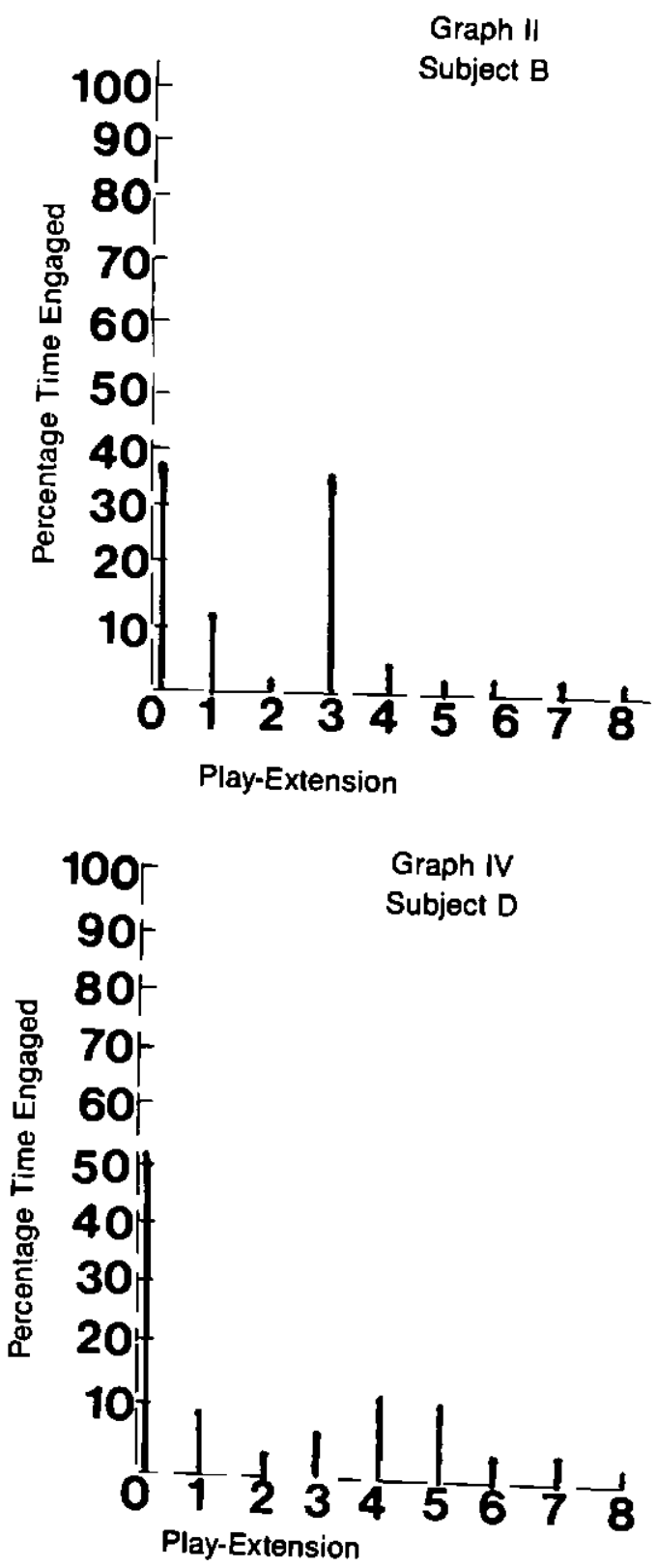

$X$ axis: $0,6 \mathrm{~cm}=1$ unit of play-extension

$Y$ axis: $0,6 \mathrm{~cm}=10 \%$ of total time

Play-Extension

0 = Play only; communication only

1 = Non-denotational

2 = Denotational

3 = Naming

4 = Play + communication accompaniment

5 = Play anticipation

6 = Play extension

7 = Play through communication + action

8 = Play replacement by means of communication

Figure 2 Percentage of

Die Suid-Afrikaanse Tydskrif vir Komminikasieafwykings, Vol. 30, 1983 
may state that "this is a moon" or even simply "moon". It cannot be assumed, however, that the non-verbal child did not intend his circle to represent a 'moon' as well. It may be argued, in the light of Piagetian research, that differences may be expected in the performance of the hearing-impaired children since verbal language is included in analysis. However, if language assumes no role during play then the hearingimpaired children should perform equivalently to their hearing peers even though language is included in rating. Findings from the first part of the study, mentioned earlier, served as a baseline for evaluating the role of language during play.

The same procedure as adopted in the derivation of the playextension scale was followed in the final rating, with percentages being obtained for each category.

\section{RESULTS}

The commonalities noted in the performance of five children (whether hearing or hearing-impaired), does not imply the presence of an underlying average. On the basis of performance of such a small sample, no inferences can be drawn with regard to performance in the general population. Only major trends both within and between the two groups of subjects, were analysed.

Since the data was nominal and not independent ${ }^{7}$ despite the superimposition of time-sampling, bar graphs were utilised to present visual displays of the most frequently occuring play and communication behaviours over time. Each child's performance was analysed individually, in accordance with case study analysis, to determine a possible developmental progression over the three two-month intervals. Since no significant differences were found to occur between the three sessions for play-extension, the results were combined and group trends only were considered. The time interval between sessions obscured the developmental changes occurring for any one subject.

The results for play-extension are represented in Figures 1 and 2. Each figure comprises five graphs, representative of the children in each group. They are ordered in terms of increasing age from top to bottom, according to a left-right-left progression on the page. Graph I on either Figure corresponds to the youngest subject in the group (subject A, Figure 1 and subject $F$ Figure 2) with graph $V$ corresponding to the oldest subject (subject E, Figure 1 and subject J, Figure 2).

It is evident from Figure 2, that subject $F$ stands apart from subjects $G, H$, I and J, the latter all displaying fluctuation over a broad range for play extension. This suggests that there is a 'levelling-off effect' for play-extension with increasing age. Once the child has reached a certain developmental stage, he is able to use the full range of levels for play-extension as measured on this particular scale. These higher levels are best considered as types with no inherent complexity grading, a flaw of the scale in that it fails to discriminate fine differences between the higher levels. The hearing-impaired children, on the other hand, demonstrated little variation from child to child with increasing age (Figure 1 , subjects $A, B$ and $C$ ), thereby yielding similar graphic displays to that for subject $F$ (Fig. 2).

In subject $E$ (Fig. 1) there is a suggestion of change which dif- fers from that of subject D (Fig. 1) and subjects G, H, I and $J$ (Fig. 2) in two ways: First, the majority of scores for subject E cluster at the lower levels as occurs for subjects A, B, C and $E$ and for subject $F$ (Fig. 2). On the other hand, subject $D$ (Fig. 1) and subjects G, H, I and J (Fig. 2) present fewer scores for levels 1 and 2, with greater numbers varying across the scale. Second, for subject E (Fig. 1) there are no examples of nonimmediacy (that is, levels 6,7 and 8) as for subjects D (Fig. 1) and subjects G, H, I and J (Fig. 2).

A consideration of individual differences affords a few possible explanations for these findings: Subjects A, B and C (Fig. 1) and subject F (Fig. 2) display clustering at the lower levels. These subjects were all at a level of vocal activity and pointing in communication. The other subjects were using either verbalisation or gesture (with or without vocalisation) as a predominant means of communication. This situation persisted from session one to session three for all subjects. In other words, no subject was using only vocal activity in the first session with a progression to verbal or gestural activity in the following session or sessions. In addition, subject $\mathrm{E}$ (Fig. 1) can be differentiated from subjects G, H, I and J (Fig. 2) and from subject D (Fig. 1), in that this subject was using gesture predominantly, whereas the other subjects were all using predominantly verbal language. Subject D (Fig. I) was using a combination of gesture and verbalisation and was thus able to attain levels equivalent to those of the hearing children.

It is difficult to draw conclusions on the basis of a single subject's performance, but it is suggested that the onset of verbalisation or gesture possibly affords the child a means of expressing himself during play, whereas verbal language affords a greater range of types for play-extension than does gesture. More particularly, all the verbal subjects attained nonimmediacy whereas subject $\mathrm{E}$ (Fig. 1) (gestural) with a small verbal vocabulary, attained only the highest level of immediacy.

There are two possible explanations for this: First, spontaneous gesture as a modality for elaboration of play through communication may not be as 'efficient' a modality as verbal language. For this reason, verbal language and gesture occur equally at the lower levels, but gesture does not occur at the higher levels. Second, subject E (Fig. 1) may be unrepresentative of the group of hearing-impaired subjects as a whole.

In order not to fall prey to experimenter bias in assuming that the communication modality is the major factor giving rise to these results, the frequencies for every vocal, verbal and gestural activity as well as combinations of these, were summated for the groups of hearing-impaired children and hearing children for all three sessions, to determine whether trends did emerge. ${ }^{18}$ It is evident that the verbal modality was used predominantly by the hearing children. Even though the hearing-impaired children did have small verbal vocabularies, they did not use verbalisation (during play) which was intelligible to the rater or to the mother. In the hearing-impaired children, gesture, with or without vocalisation, was frequently used (as compared with the dearth of gestures displayed by the group of hearing children). However, the higher levels for nonimmediacy (levels 6,7 and 8 for play-extension) were never attained by the hearing-impaired children. Finally, vocal activity predominated in the hearing-impaired group as opposed to verbal activity for the hearing group. 
These trends suggest that the communication modality is an important differentiating factor determining levels of performance for play-extension. The type of communication affected the levels or types of play-extension obtained. More importantly, they suggest that communication is closely related to play, that the hearing child uses verbal language to enhance his play, and that the hearing-impaired child, though he uses gesture in the same way, cannot attain equivalent levels. The scale used provided a differentiation of levels for playextension (as evident in subjects $\mathrm{D}, \mathrm{H}$ and $\mathrm{I}$ ).

These findings suggest that verbal language may be important in the early cognitive stages. This is contrary to Piaget's view ${ }^{12}$ that language affects cognition only at the higher stage of logical operations. It is evident that communication and play are integrally related and that separation of these processes provides only a partial indication of the picture of play as a whole. ${ }^{19}$ Verbal language was used by the hearing children to enhance their play. However, the hearing-impaired children did not compensate by means of spontaneous gesture although they might have displayed nonimmediacy had they been competent in sign language.

\section{DISCUSSION}

From the preliminary study (mentioned earlier), it was evident that language did not prevent the attainment of symbolic play. Since symbolic play is regarded as one form of abstracting $^{21}$, it is evident that these hearing-impaired children were able to abstract within a non-verbal context. The findings for play-extension indicated that language was used by hearing children during play to extend beyond the immediacy of the play materials as well as to accompany and to anticipate play activities. The hearing-impaired children used gesture similarly, to accompany and to anticipate play activities, but no examples of nonimmediacy were present in their performance. In other words, they did communicate during play but communication was not used for the purpose of 'abstracting' or 'moving away from' as used by the hearing children. These findings suggest that language does assume a role during play.

Children with predominantly vocal activity were still able to engage in symbolic play but only those who possessed verbal facility engaged in play-extension. In accordance with the view that language and symbolic play arise during the same developmental stage, (Piaget's pre-operational stage), it was found that only those children who had reached this cognitive stage engaged in play-extension. It must be kept in mind that complete exclusion of language (that is, the child's knowledge
of language) is not possible in assessment.

These findings suggest a need to reconsider the role of language in play development. The terms 'symbolic play' and 'imaginative play' must be viewed within the framework in when regarded conceptualised; they are not equivalent, but pean or Soviet in universal terms, independent of the Euroa loose integration: Play-ext orientations, they seem to afford of the term 'imation: Play-extension approaches Vygotsky's use as used by Piaget ${ }^{2}$ play', ${ }^{21}$ with the term 'symbolic play' has been detailet, ${ }^{2}$ forming a subset of this category. This mind that the term "imate by Segal, ${ }^{19}$ but it must be kept in Die Suid-Afrikan term "imaginative play" as used in the present study, is not equivalent to Vygotsky's original use of the term, since the latter occurred within a Soviet framework.

Even in the early cognitive stages, the hearing-impaired children did not attain levels comparable to their hearing peers and the cumulative effects of delayed and different performance with further development, cannot be ignored. Furthermore, the acquisition of processes in the 'different' child may not be as linear as that for the 'normal' child with regard to stages. ${ }^{15}$

The disagreements between the different educational approaches to hearing-impaired children are highlighted in the present findings. The hearing-impaired children may have failed to use language to extend play because gesture is not as efficient a medium as verbal language in this regard. Sign language may be a suitable medium for play-extension or, it may afford the child a modality for increased communication during play but not for play-extension (that is, verbal language may be the necessary modality for play-extension). Further research is required to elucidate this issue.

Arising from the above discussion, the findings and methodologies of previous researchers require additional consideration., 23 The previous emphasis on the ease of acquisition of actions in symbolic play versus language appears to be less enlightening with regard to the hearing-impaired child than the gestural link between symbolic play and communication. The hearing-impaired child's delayed rather than different performance and his ability to engage in symbolic play, seems to negate the possibility of a general representational deficit. The present findings support the view outlined by Arnold,' that verbal language is not required for cognitive development in hearing-impaired children. However, the cumulative effects of delayed language may contribute to later difficulties at the level of logical operations.

Cognizance must be taken of the close relation existing between language, symbolic play and gesture when dealing with all 'language-different' children. Play, being both nonverbal and observable, appears to be a useful clinical tool affording differential diagnosis of language abilities. (For detailed diagnostic and therapeutic implications, see Segal ${ }^{20}$ ). Playextension may provide a means of conveying the principle of abstracting to hearing-impaired children with regard to both the play context and the use of language. Qualitative analysis affords the derivation of a clinical profile of each child's cognitive, communicative and play-extension abilities, and provides for therapeutic direction. ${ }^{20}$

The relation between communication and play is still relatively unexplored in normal children as evidenced in a comprehensive review of the field of play by Fein. ${ }^{4}$ The few studies that have dealt with language, communication, or metacommunication and play (for example, Nicolich and

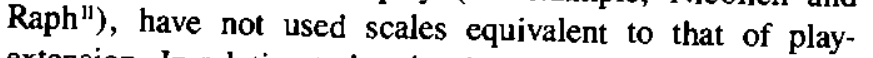
extension. In relation to hearing-impaired children, this field remains in its infancy. Implications for future research include longitudinal investigations of play and communication with large samples of normal and hearing-impaired children to afford detailed comparisons across groups; pertinent diagnostic indicators separating groups, for example, language-impaired from hearing-impaired children (using play analysis as the 
major assessment tool); similarities and differences between verbal language and sign language in relation to play; and testretest reliability measures. In addition, longitudinal studies would indicate whether symbolic play and play-extension parallel each other in development thereby giving rise to two branches in the cognitive sphere which may affect different logical processes at a later stage. ${ }^{18}$

In a relatively unexplored field of research, it is hoped that this study will serve as an incentive for subsequent investigations.

\section{ACKNOWLEDGEMENTS}

This paper is based in part on a section of a Masters dissertation submitted to the University of the Witwatersrand, Johannesburg. The writer expresses her gratitude to Prof. M. L. Aron and Dr. C. Penn who served as supervisor and informal adviser respectively. In addition, the writer wishes to acknowledge the financial assistance received from The University of the Witwatersrand, the Human Sciences Research Council and the South African Speech and Hearing
Association.

\section{REFERENCES}

1. Arnold, P. Ph.D. (1979). Changing Views of the Deaf Child. Journal of the British Association of Teachers of the Deaf, 3(6), 178-192.

2. Bruner, J. S. (1966). On Cognitive Growth I, II. Chaps. I and 2 in Studies in Cognitive Growth, Bruner, J. S., Olver, R. R. and Greenfield, P. M. (Eds.), John Wiley, New York; Pp. 1-67.

3. Eibl-Eibesfeldt, I. (1970). Ethology: The Biology of Behaviour. Holt, Rinehart, Winston, New York.

4. Fein, G. G. (1981). Pretend Play in Childhood: An Integrative Review. Child Development, 52, 1095-1118.

5. Goldin-Meadow, S. \& Feldman, H. The Creation of a Communication System: A Study of Deaf Children of Hearing Parents. Sign Language Studies, -8, 225-236, 1975.

6. Lunzer, E. A. (1959). Intellectual Development in the Play of Young Children. Educational Review, 11, 205-217.

7. McCall, R. B. (1970). Fundamental Statistics for Psychology. Harcourt, Brace and World, U.S.A.

8. Mehrabian, A. (1972). Nonverbal Communication. Aldine-Atherton, Chicago, U.S.A.

9. Millar, R. (1968). The Psychology of Play. Penguin Books, Harmondsworth, England.

10. Miller, R. (1976). The Development of Competence and
Denise S. Segal

Behaviour in Infancy. Unpublished Doctoral Thesis Sub. mitted to the Faculty of Arts, University of the Witwatersrand, Johannesburg, South Africa.

11. Nicolich, L. \& Raph, J. (1978). The relation of Symbolic Maturity as Observed in Play to Spontaneous Vocal Imita tion in Early Language Development. Journal of Psychol. inguistic Research, 7, 401-417.

12. Piaget, J. (1951). Play, Dreams and Imitation in Childhood. Routledge and Kegan Paul, London.

13. Piaget, J. (1966). Response to Brian Sutton-Smith. Chap. 22 in Child's Play, Herron, R. and Sutton-Smith, B., (Eds.), John Wiley, New York; 1971.

14. Power, D. J. \& Quigley, S.P. (1973). Deaf Children's Acquisition of the Passive Voice. Joumal of Speech and Hearing Research, 16, 5-11.

15. Prutting, C. A. (1979). Process /p̀ră/, ses / n: The Action of Moving Forward Progressively from one Point to Another on the Way to Completion. Journal of Speech and Hearing Disorders, XLIV, 3-30.

16. Prutting, C. A. \& Skarakis, E. A. (1971). Communication Development. Chap. 13 in Audiometry in Infancy, Gerber, S. A. (Ed.), Grune and Stratton, New York; Pp. 247-262.

17. Segal, D. (1980a). Relationship between Verbal Language and Symbolic Play - A Case Study. The South African Joumal of Communication Disorders, 27, 37-55.

18. Segal, D. (1980b). Symbolic Play and Communication in Congenitally Hearing-Impaired Children. Unpublished Dissertation Submitted to the Department of Speech Pathology and Audiology, University of the Witwatersrand, Johannesburg, South Africa.

19. Segal, D. (1982). Symbolic Play and Communication in Hearing-Impaired Children: Piaget and Vygotsky Reconsidered. The South African Journal of Psychology, 12, 111-116.

20. Segal, D. (in press). Play and Communication - A Cognitive-Based Approach to Language Therapy for the Hearing-Impaired Child. Joumal of the British Association of Teachers of the Deaf.

21. Vygotsky, L. S. (1933). Play and its Role in the Mental Development of the Child. In Play - Its Role in Development and Evolution, Bruner, J. S., Jolly, A. and Sylva, K., (Eds.), Penguin Books, Harmondsworth, England. 1976, Pp. 537-554.

22. Watts, W. J. (1970). The Developmental Theory of Jean Piaget and the Deaf Child. Teacher of the Deaf, 68 , 372-383.

23. Werner, H. \& Kaplan, B. (1963). Symbol Formation: An Organismic-Developmental Approach to Language and the Expression of Thought. John Wiley, New York. 